\title{
Didáctica de los órganos del sistema digestivo en niños de 4 años. Importancia de una correcta evaluación inicial en educación infantil
}

DOI: $10.46932 / \mathrm{sfjdv2n1-069}$

Received in: November 1st, 2020

Accepted in: December 30th, 2020

\author{
Jose María Rabal Alonso \\ Profesor ISEN Centro Universitario \\ Institution: Universidad de Murcia \\ Calle Campus Universitario, 12, 30100 Murcia \\ E-mail: josemaria.rabal@um.es \\ Laura Martínez Gallego \\ Graduada Educación Infantil \\ Institution: RG Formación \\ Calle Rosalía de Castro, 44, 30107 Murcia
}

\begin{abstract}
RESUMEN
Desde nuestro punto de vista, resulta fundamental que desde edades tempranas los niños comiencen a conocer su cuerpo, las partes que lo forman y en concreto, tal y como muestra este trabajo, los distintos sistemas, aunque nosotras nos centremos en el digestivo. El motivo por el que hemos elegido este sistema, es porque consideramos que su comprensión resulta más sencilla para los niños, dado que, manifiestan mayor curiosidad por diversos conceptos relacionados con el mismo. Por otro lado, se trata de un tema que está presente en sus vidas, y que los pequeños ven de forma natural, frente a la opinión de algunos adultos que intentan censurarlo o tratarlo sin naturalidad. Consideramos que resulta positivo que determinados aspectos vinculados a este sistema como es el caso de la expulsión de residuos del cuerpo humano, se traten desde un comienzo en la etapa educativa, ya que al iniciar sus estudios preescolares, generalmente, los alumnos todavía no tienen un total control de esfínteres. Además, existen otras concepciones sobre este sistema que pueden resultar más familiares para el alumnado, aunque no lleguen a comprender del todo qué es, cómo en el caso del estómago.
\end{abstract}

Palabras clave: organización escolar, teoría educativa, aprendizaje significativo, contexto próximo.

\section{INTRODUCCIÓN}

El tema en el que se centra nuestro trabajo es el sistema digestivo, ya que, consideramos que es uno de los sistemas del cuerpo humano más conocido por los niños. Tal y como se señala en el Decreto 254/2008, 1 de agosto, por el que se establece el currículo del Segundo Ciclo de la Educación Infantil en la Comunidad Autónoma de la Región de Murcia, en relación al BLOQUE 1, El cuerpo y la propia imagen situado dentro del área Conocimiento de sí mismo y autonomía personal, podemos hacer referencia al siguiente objetivo: 
- Conocer y representar el cuerpo, diferenciando sus elementos y algunas de sus funciones, descubriendo las posibilidades de acción y de expresión, y coordinando y controlando cada vez con mayor precisión gestos y movimientos.

Creemos que este objetivo está incluido en nuestro trabajo, ya que, en la entrevista que realizaremos a los alumnos se les planteará una serie de preguntas en torno al sistema digestivo, en concreto, sobre el órgano del estómago, su ubicación y el funcionamiento del mismo, para conocer qué saben acerca de este. Además, de forma indirecta se hace mención a los intestinos mediante preguntas sobre la expulsión de desechos del organismo, cuestionando también la función de estos últimos.

\section{2 ¿CUÁL ES EL PROBLEMA?}

Nuestro trabajo se centrará en averiguar qué ideas tienen acerca del sistema digestivo en ese momento los alumnos a los que entrevistaremos. Para ello, realizaremos de manera individual una serie de preguntas. Una de ellas, estará apoyada por una ficha, en la que, se muestra la silueta del cuerpo humano para que ellos puedan trazar con pintura el recorrido que hace un alimento desde que se ingiere. La otra ficha utilizada no se encontrará relacionada con una pregunta directa pero se utilizará para recabar información.

Como hemos mencionado anteriormente, nos centraremos en el conocimiento que poseen algunos niños del órgano del estómago, incluido en el sistema digestivo, así como la función de los intestinos dentro de dicho sistema para la función excretora.

\section{3 ¿CUÁLES SON VUESTRAS PREDICCIONES?}

De acuerdo a nuestras consideraciones previas a la entrevista, creemos que nos dirán que dentro de la barriga se albergan un número de elementos aleatorios como comida, gases o desechos.

Por otro lado, creemos que los niños de 4 años conocerán lo que es el estómago y dónde se encuentra, ya que pensamos que sabrán colocar el gomet correctamente en el lugar que corresponde en la silueta. Sin embargo, la cuestión del tamaño puede generar dudas y no sabrán determinar cuál es su tamaño, ni la función que tiene. Además, es posible que a través de la reformulación de algunas preguntas, puedan llegar a hacerse una idea de para qué sirve el estómago, pero en un principio, por iniciativa propia, no creemos que sepan decirlo.

También, consideramos que sabrán seguir un correcto recorrido realizado por un plátano desde el momento que lo ingerimos, dibujando con pintura el trayecto que sigue el mismo, en una silueta que le proporcionaremos en blanco. 
Para finalizar, creemos que responderán de forma afirmativa a la pregunta referente a la expulsión de los alimentos del organismo, sabrán decir a dónde van a parar.

\section{PLANIFICACIÓN DE LA RECOGIDA DE LOS DATOS DISEÑO DE LA ACTIVIDAD}

\subsection{DISEÑAR LAS PREGUNTAS DE LA ENTREVISTA Y PLANIFICAR UNA ESTRATEGIA PARA} DESARROLLAR LA CONVERSACIÓN.

- ¿Qué crees que tienes en la barriga?

- ¿Dónde crees que está el estómago?,¿crees que es grande o pequeño?

- ¿Para qué crees que sirve el estómago?

- Cuando te comes un plátano, ¿por dónde crees que pasa?

- ¿Crees que la comida sale por algún sitio?

- ¿A dónde va?

Utilizaremos comentarios de estímulo al final de cada pregunta con el fin de motivarles a que continuen exponiendo sus opiniones, tales como: ¡Muy bien!, ¡sabes mucho!, etc.

Además, haremos uso de estrategias de persuasión en el caso de que los alumnos se mantengan en silencio o no lleguen a entender por completo la formulación de las preguntas. En el caso de la pregunta en la que deben indicar el recorrido de un alimento, podríamos ayudarles ampliando el número de preguntas, facilitándoles la esquematización del recorrido en varios tramos antes de unirlo en un único tramo final. Algunos ejemplos en los que hemos pensado son los siguientes: ¿por dónde entra la comida cuando la comes?, ¿hasta dónde llega?.

Por otro lado, utilizaremos preguntas de reformulación con el objetivo de que los alumnos expliquen lo que han realizado en sus dibujos o para que vayan recordando la información que nos han dado de forma oral. También haremos uso de la reformulación en las situaciones en las que los alumnos permanezcan en silencio si aportarnos respuestas. Algunos ejemplos serían: ¿crees que está vacía?; y para comprobar si se reafirman en la respuesta dada, preguntaremos, ¿crees que no sale nada? ¿se queda la comida dentro?

\subsection{DISEÑAR LOS MATERIALES EN LOS QUE VAYÁIS A APOYAR LOS DIÁLOGOS DURANTE LA ENTREVISTA O CUALQUIER OTRO MATERIAL QUE PENSÉIS UTILIZAR. \\ Haremos uso del dibujo de dos siluetas del cuerpo. La primera de ellas (ANEXO I) la utilizaremos para que los alumnos marquen dónde se encuentra el estómago con un gomet tras la pregunta “¿Dónde crees que está el estómago?”. La segunda silueta tendrá una orientación lateral de la cabeza (ANEXO II)}


para que puedan identificar más fácilmente la boca, lugar por el que introducen el alimento, ya que el planteamiento para que realicen la actividad es “Cuando te comes un plátano, ¿Por dónde crees que pasa?” , y de este modo, hacer referencia al recorrido que hace la comida dentro del cuerpo una vez introducido en él.

\subsection{CONSULTAR A PADRES Y/O PROFESORES Y MOSTRARLES VUESTRA INTENCIONALIDAD AL REALIZAR LAS ENTREVISTAS/DIÁLOGOS/CONVERSACIONES.}

En primer lugar, la compañera acudió al centro a hablar con el director del mismo para solicitar el permiso necesario para realizar dicha actividad. Una vez que le explicó en qué consistía la actividad y obtuvo el permiso para realizarla, habló con la tutora del grupo en el que se realizaría la entrevista, en este caso, un grupo de 4 años. La maestra aceptó de inmediato la petición de la compañera y una vez seleccionados los niños a estudiar, volvió a dirigirse al director y ambos prepararon unas autorizaciones a firmar por parte de los padres de los niños interesados. (ANEXO III).

Una vez redactadas las autorizaciones, la tutora del grupo se encargó de entregárselas en mano a los padres y de explicarles la situación de estudio con el fin de motivarlos a participar. En ese momento consiguió que algunos de los padres firmasen allí mismo, el resto se encargó de recogerlo durante los días previos a la entrevista, y se mantuvo en contacto con la compañera para decidir qué día asistir a realizar y para informarle cuando dispusiese del permiso de todos los padres de los alumnos solicitados.

4.4 SELECCIONAR A LOS NIÑOS DE DISTINTAS EDADES Y EL LUGAR EN EL QUE SE DESARROLLARÁN LAS ENTREVISTAS. CADA GRUPO DEBERÁ, AL MENOS, ENTREVISTAR A TANTOS NIÑOS COMO COMPONENTES TIENE. SI ES POSIBLE, HACERLO REUNIENDO A TODOS LO NIÑOS, SI NO LO ES PUEDE TRATARSE DE CONVERSACIONES INDIVIDUALES.

El aula que hemos escogido para desarrollar este trabajo es la de 4 años, habiendo elegido a seis niños para realizar la entrevista, la cual se llevó a cabo en la sala de profesores de Infantil del centro en el que se realizó la misma. Las entrevistas se desarrollaron de forma individualizada para evitar que unos niños copiaran las respuestas de otros y para que la recogida de información fuese más efectiva, ya que se centraría la atención en el niño entrevistado y se evitaría recibir varias respuestas al mismo tiempo por parte del resto de niños, lo que facilitaría el recabar la información proporcionada por los niños sin dar lugar a errores, confusiones entre el alumnado, o repeticiones innecesarias que alargarían la entrevista. Consideramos que de esta forma los niños podrían sentirse más participativos y responderían de una forma más sincera y menos cohibida por las respuestas que pudiesen expresar otros compañeros. 


\subsection{ESTABLECER TÉCNICAS DE RECOGIDA DE LA INFORMACIÓN QUE DAN LOS NIÑOS} (GRABACIONES, VIDEOS, ETC).

Las respuestas de los alumnos serán recogidas en un archivo de audio ya que se grabará toda la conversación mantenida con ellos durante la entrevista. Además, mediante las fichas de las siluetas mencionadas anteriormente, también obtendremos información, ya que estarán representando sus opiniones mediante el dibujo (ANEXO IV) o mediante la colocación de un gomet en forma de simulación (ANEXO V)

\section{RESULTADOS DE LA INVESTIGACIÓN}

\subsection{REALIZACIÓN DE LAS ENTREVISTAS (RECOGIDA DE DATOS).}

Las entrevistas fueron realizadas de forma individualizada durante un tiempo máximo de 15 minutos por niño.

A continuación pasaremos a mostrar la transcripción de la entrevista realizada a cada uno de los alumnos. En la misma, se incluirán dos colores diferentes, para distinguir la intervención de la compañera que plantea cada una de las cuestiones, y las respuestas dadas por cada uno de los niños.

\section{PREGUNTAS}

RESPUESTAS

NIÑO 1 "Voy a hacerte unas preguntas para ver cuánto sabes de tu cuerpo, y vamos a hacer una ficha, Vale?" “A ver, ¿tú qué crees que tienes en la barriga?

Mmmm, no sé... ¿la sangre? La sangre... ¿algo más? Mmm... Lo que tú creas. ¿La comida? La comida, por ejemplo, muy bien. ¿Crees que hay algo, no? La sangre, la comida... ¿Los huesos? Los huesos, vale. Te voy a dar esta silueta, es la de una persona mayor... y ahora quiero que tú me pegues un gomet donde tú creas que está el estómago. Coge uno. (OBSERVAR FICHA). Muy bien. ¿Y tú, cómo crees que es de grande el estómago? Eh... ¿mediano? ¿Me señalas con las manos el tamaño que tú creas que tenga?

Muy bien, ahora, ¿tú para qué crees que sirve el estómago? Para... ¿tragar? Para tragar... (silencio). Me has dicho que dentro de la barriga... ¿qué teníamos? La comida, la sangre y los huesos. ¿Dónde ubicarías la barriga? ¿En el pie? (después señala su barriga) Entonces si en la silueta has colocado aquí el...? (no responde) estómago, y está dentro de la barriga, ¿para qué crees que sirve? (silencio) ¿No lo sabes? No. Vale, no pasa nada.

Ahora te voy a dar esta silueta y yo te digo Cuando tú te comes un plátano, ¿tú comes plátanos? Sí. Vale, pues cuando tu te comes un plátano, ¿por dónde crees que pasa? Quiero que me lo señales aquí con pintura. 
Moja el dedo y me lo señalas. (OBSERVAR FICHA, MARCA EL ESTÓMAGO Y LUEGO BAJA HASTA LA PIERNA “PARA QUE ME DÉ FUERZA EN LOS PIES” Vale, pero cuándo lo comes ¿por dónde entra? (Señala el pie) ¿Por aquí? ¿Tú te comes un plátano por los pies? No, por la boca. A ver, señálame el camino. Si entra por la boca... házmelo con pintura. Muy bien, vale.

Entonces, ¿tú crees que la comida, después de comerla sale por algún sitio? No. ¿Crees que no sale? ¿Tú crees que la comida cuando la comemos se queda dentro de la barriga? ¿No va a ningún sitio? Eh... yo no sé a dónde va. Vale, pues muy bien, hemos terminado, vamos a clase.

\section{NIÑA 2}

Te voy a hacer unas preguntas para ver cuánto sabes tú sobre tu cuerpo, y luego vamos a hacer unas fichas, ¿vale? A ver, ¿tú qué crees que tenemos en la barriga, dentro?

Sangre. Sangre, ¿algo más? Huesos. Huesos... ¿sangre y huesos? ¿ya está? (Asiente) Vale, muy bien.

A ver, yo te voy a dar esto, que es una silueta de un cuerpo ¿vale? Y quiero que me pegues un gomet donde tú creas que está el estómago. (OBSERVAR FICHA) Vale, y tú... ¿cómo crees que es de grande? Se hace grande comiendo fruta. (ANÉCDOTA) Pero tú ¿cómo crees que es de grande? Señálamelo con las manos, como crees que es su tamaño (Alargado hacia arriba) Vale, muy bien. ¿Y para qué crees que sirve el estómago? Pues para tragar. Para tragar... ¿sólo? Sí.

Entonces, mira, te doy ahora esta silueta. Moja el dedo. Tú cuando te comes un plátano, ¿por dónde crees que pasa? Señálamelo con pintura. Hazme el recorrido. (Marca un solo punto) ¿Cuándo te lo comes, por dónde pasa? ¿Así? Sí, como tú creas. Tu piensa que este es el cuerpo, ¿por dónde entra el plátano? (OBSERVAR FICHA) Muy bien, hasta donde tu creas que llega el plátano. Vale, entonces. ¿tú crees que cuando te comes un plátano llega hasta el pie? Sí. ¿y que te lo tragas por...? ¿Qué habías puesto aquí? La garganta. ¿Y qué señalaba este gomet? El estómago.

Bueno entonces, si crees que llega al pie, ¿crees que luego la comida sale por algún sitio? (Señala el pie) Mmm, ¿pero crees que sale del cuerpo? No. Vale, pues muy bien, vámonos a clase.

NIÑA 3 Te voy a hacer unas preguntas para ver cuánto sabes tú sobre tu cuerpo, y luego vamos a hacer unas fichas, ¿vale? ¿Tú qué crees que tienes en la barriga? Eh... Lo que tú pienses, dime lo que creas. El cerebro. ¿Algo más? (Silencio) ¿Tú dónde crees que está la barriga? Señálala en tu cuerpo. (La indica bien) ¿y qué crees que hay ahí dentro? (Silencio) Me has dicho el cerebro... ¿algo más? El cuello, los ojos... ¿Los ojos? ¿Dónde estaba la barriga, que me la has señalado? (Vuelve a indicarlo) ¿Y tú ahí tienes ojos? No. ¿Entonces qué crees que hay ahí aparte del cerebro y del cuello? No hay nada más.

Mira, te voy a dar esta silueta de un cuerpo y te voy a dar un gomet para que lo pegues donde tú creas que está el estómago. (OBSERVAR FICHA). Muy bien... y tú ¿cómo crees que es su tamaño? 
Señálamelo con las manos. Pequeño. ¿Y si está aquí para qué crees que sirve? ¿Qué hace el estómago? (Silencio) ¿Crees que hay algo dentro del estómago? Está vacío. O sea, ¿Que no sirve para nada? Sí sirve, sirve para tragar. Vale, muy bien...

Entonces, si sirve para tragar, si yo te doy esto, otra silueta de un cuerpo, y yo te digo cuándo tú te comes un plátano ¿por dónde crees que pasa? Dentro de cuerpo, ¿por dónde crees que pasa el plátano? (OBSERVAR FICHA) Señálalo con pintura. (Indica la garganta) ¿Crees que se queda ahí? (Continua el camino hasta la barriga) ¿Te acuerdas de qué era esto? Que lo habías señalado antes aquí (enseño la ficha del gomet) La barriga. Muy bien, la barriga. Entonces, el plátano llega a la barriga, y luego... ¿tú crees que luego la comida sale hacia afuera? No. ¿No sale del cuerpo? ¿Crees que la comida se queda ahí en la barriga? Sí. Muy bien, vamos a clase.

NIÑO 4 Mira te voy a hacer unas preguntas para ver cuánto sabes sobre tu cuerpo ¿vale? ¿Tú qué crees que tienes dentro de la barriga? (Silencio) ¿Crees que está vacía? Sí. ¿Entonces no crees que tenemos nada dentro? Está vacía.

Vale pues, te voy a dar esta silueta del cuerpo y quiero que me pegues un gomet donde tú creas entonces que está el estómago. (OBSERVAR FICHA). Muy bien... entonces, ¿cómo crees que es de grande el estómago? Señálamelo con las manos. Pequeño. (Muy pequeño, junta los dedos) Vale, y ¿para qué crees que sirve el estómago? ¿Qué crees que hace? (Silencio). ¿Hace algo? Sí. ¿Y si hace algo, que crees que hace? Siempre me suena cuando yo quiero comer. (anécdota) ¿Entonces, qué crees que hay ahí? ¿Cómo solucionas esa hambre? Como. ¿Entonces..., sirve para que te avise cuando tienes hambre? Sí.

Vale, pues mira, te voy a dar ahora esta silueta y yo te digo, cuando tú te comes un plátano, ¿por dónde te lo comes? (Marca la boca). Muy bien, y ¿a dónde crees que va el plátano cuando nos lo comemos? ¿Por dónde pasa del cuerpo? Señálalo con pintura. (OBSERVAR FICHA) ¿Crees que va al pie? Sí. Entonces, tú crees que entra por la boca y llega hasta el pie. ¿Qué quiere decir este camino? ¿Por dónde entra el plátano? Por la boca. (señala el dibujo y dice que llega hasta el pie).

Vale, y si nos llega hasta el pie, ¿tú luego crees que la comida sale por algún sitio? (se ríe con vergüenza). ¿Crees que sale o no sale? No sale. Vale, pues muy bien, vámonos a clase.

NIÑA 5 A ver, tú ¿qué crees que tienes dentro de la barriga? Eh... Dime lo que tú creas. Dentro de la barriga. ¿Sabes dónde está la barriga? Señálamela. (LA INDICA) Muy bien, entonces, ¿qué crees que tenemos dentro? Eh, comida. Comida, muy bien. ¿Algo más? Eh... bebida. Muy bien ¿crees que hay algo más? No. ¿Entonces qué tenemos? Comida y bebida. 
Muy bien, ahora te voy a dar esto, que es la silueta de un cuerpo y quiero que me pegues un gomet donde tú creas que está el estómago. (OBSERVAR FICHA). Muy bien, y ¿cómo crees que es su tamaño? señálalo con las manos. Grande. ¿Así, tan grande? Vale muy bien. Entonces, ¿para qué crees que sirve el estómago? ¿para qué crees qué está ahí? Para la comida. ¿Pero hace algo? No.

Vale, mira, te voy a dar esta otra silueta y te digo, cuando tú te comes un plátano ¿por dónde pasa? ¿a dónde llega el plátano? En la barriga. Muy bien, señálame el camino que hace el plátano con pintura. (OBSERVAR FICHA). Pero, ¿entra por algún sitio? ¿por dónde te lo comes? Por la boca y entra a la barriga. Muy bien, entonces me has dicho que llega ¿a dónde? A la barriga.

Muy bien, entonces ¿tú crees que luego la comida sale por algún sitio? Por la barriga. Llega a la barriga, pero ¿sale fuera del cuerpo? Sí, por el cuerpo (señalándose la espalda). Vale, pues muy bien, nos vamos a clase. Muy bien, sabes mucho.

NIÑO 6 Mira, te voy a hacer unas preguntas para ver cuánto sabes tú sobre tu cuerpo. A ver, ¿tú qué crees que tienes dentro de la barriga? Comida. ¿Algo más? Es que no sé. ¿Crees que sólo hay comida? Sí. Vale, pues dime lo que sepas.

Ahora te voy a dar esta silueta de un cuerpo y quiero que me pegues un gomet donde tú creas que está el estómago. (OBSERVAR FICHA). Vale, entonces, ¿cómo crees que es su tamaño? Házmelo con las manos. Grande. Vale, y ¿para qué crees que sirve el estómago? Para tragar. Muy bien, ¿por eso lo has colocado aquí? Sí.

Vale, ahora te doy esta silueta y te pregunto cuando tú te comes un plátano ¿por dónde crees que pasa dentro de tu cuerpo? Por la barriga. A ver, márcame el inicio. ¿Por dónde te comes el plátano? (OBSERVAR FICHA, SELECCIONA LA MANO). No sé. A ver, tú cuando comes ¿por dónde entra la comida? Por la boca. Muy bien, entonces ¿por dónde entra el plátano? Por la boca. Muy bien, y cuando entra por la boca, ¿a dónde va? A la barriga. Muy bien.

Y luego, cuando llega a la barriga ¿tú crees que luego la comida, el plátano, sale por algún sitio? Por el culo. Muy bien, entonces, si sale por el culo... ¿se queda en la barriga o sigue otro camino? (apoyada en su ficha) Sigue otro camino (lo marca). Entonces, me has señalado que entra por ¿la? Boca. Y sigue ¿por? La barriga. ¿y sale por? El culo. Muy bien, entonces ¿a dónde va si sale por el culo? A los pies. Si sale FUERA, ¿a dónde va? Al váter. Muy bien, vámonos a clase, sabes mucho, está genial. 


\subsection{REPRESENTACIÓN E INTERPRETACIÓN DE LOS DATOS (ORGANIZACIÓN DE LA} INFORMACIÓN RECOGIDA).

En la investigación que hemos llevado a cabo, los datos obtenidos fueron recogidos a través de diferentes preguntas orales, acompañadas algunas de ellas de las fichas de apoyo.

- Primera pregunta: ¿Qué crees que tienes en la barriga?

En la entrevista que realizamos, en primer lugar, decidimos preguntarle a los niños que si creían que tenían algo dentro de la barriga, para que a raíz de sus respuestas, pudiéramos enfocar las preguntas de un modo u otro. En este caso, de los seis niños a los que entrevistamos dos de ellos respondieron que tenían comida, uno que tenía huesos, sangre y comida, otro que sólo tenía sangre y huesos, otro que en la barriga estaba el cerebro y por último, otro respondió que esta estaba vacía.

Figura 1. Resultados a la cuestión ¿Qué crees que tienes en la barriga?

\section{¿QUÉ CREES QUE TIENES EN LA BARRIGA?}

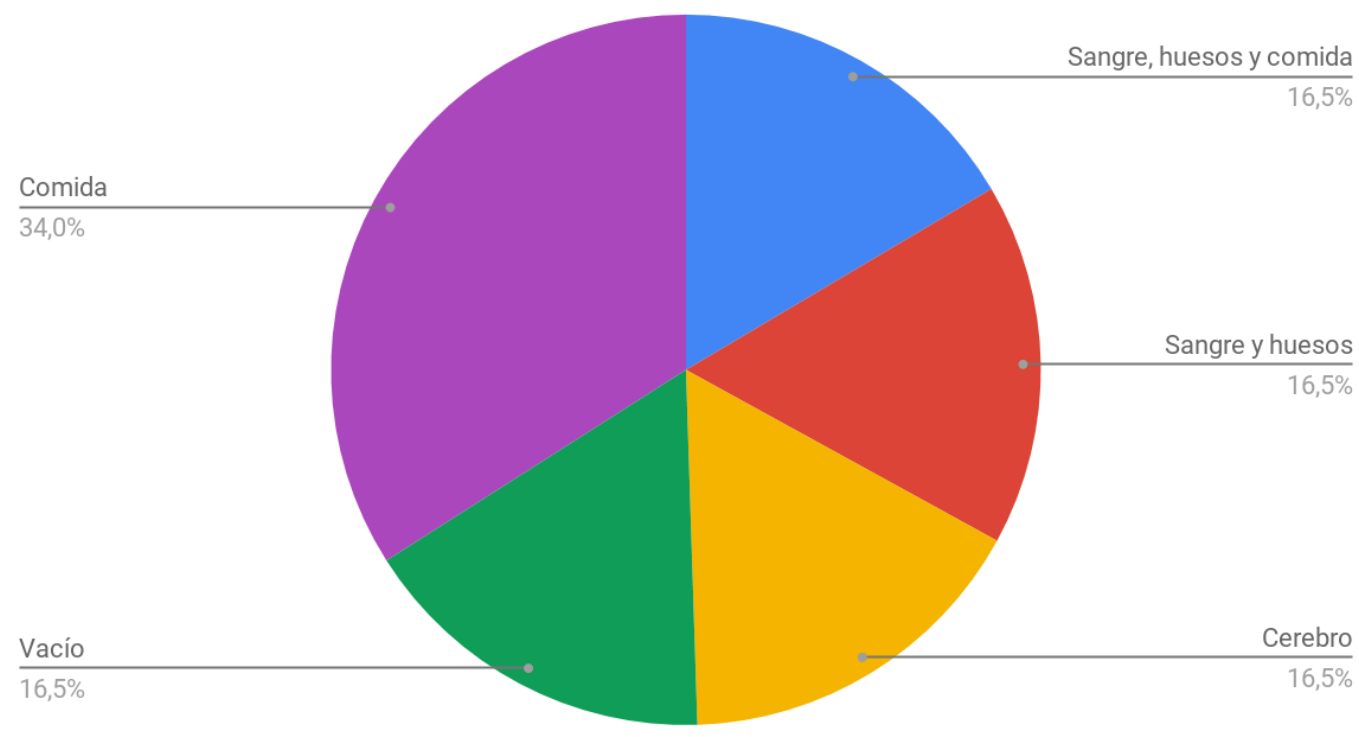

- Segunda pregunta: ¿Dónde crees que está el estómago?

En esta segunda pregunta, queríamos comprobar si los niños sabían dónde se encontraba el estómago dentro su cuerpo, para verificar además si encontraban alguna relación con la barriga. Para ello, hicimos uso de una silueta del cuerpo humano en la que los niños tenían que colocar un gomet en la zona en la que creyesen que estaba el estómago. Cuatro de los niños colocaron el estómago en el medio del cuerpo, es decir, en la zona en la que se encuentra la barriga. Sin embargo, los dos restantes colocaron el gomet en la zona de la garganta. 
Figura 2. Resultados a la cuestión ¿Dónde crees que está el estómago?

\section{¿DÓNDE CREES QUE ESTÁ EL ESTÓMAGO?}

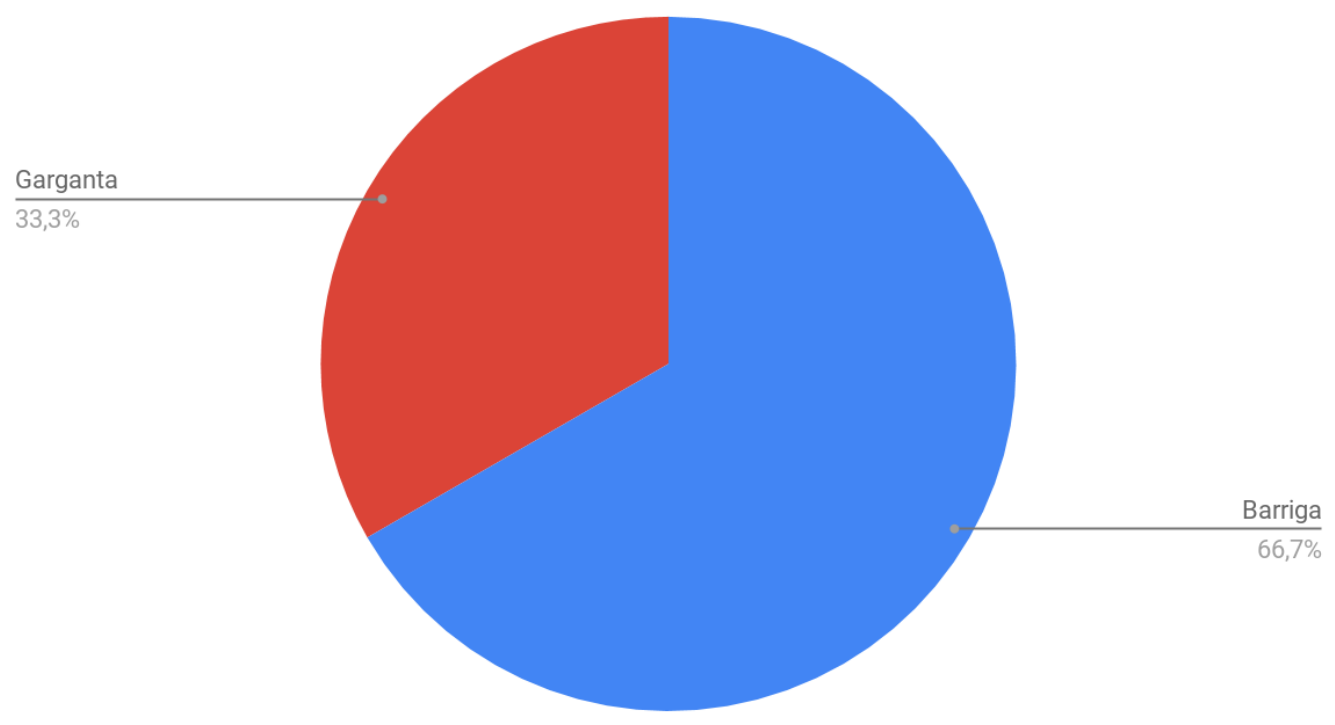

- Tercera pregunta: ¿Cómo crees que es de grande?

En la tercera pregunta, una vez que en la cuestión anterior han situado con un gomet el estómago, se les ha preguntado sobre el tamaño del mismo, para ver qué ideas pueden tener de su tamaño. Uno de los niños sugirió que el tamaño del estómago era mediano, dos de ellos dijeron que era pequeño y los tres restantes, dijeron que su tamaño era grande.

Figura 3. Resultados a la cuestión ¿Crees que es grande o pequeño?

\section{¿CREES QUE ES GRANDE 0 PEQUEÑO?}

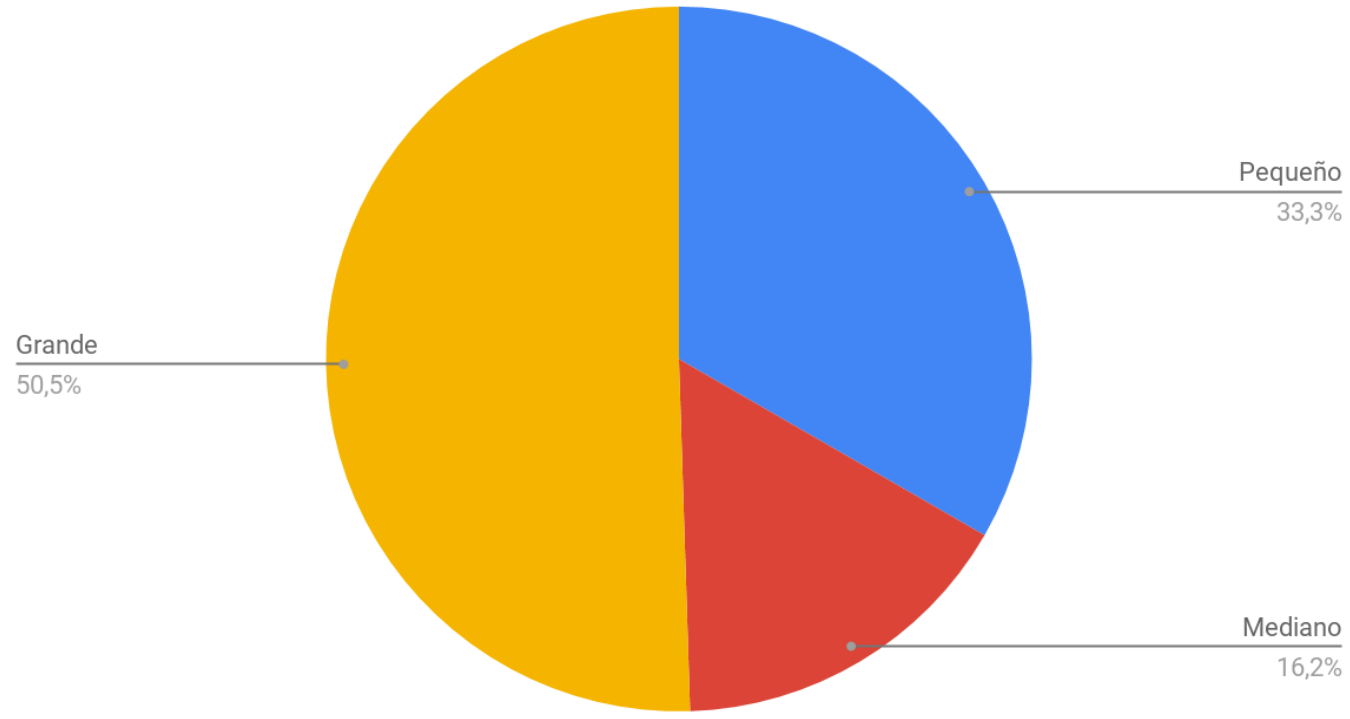


- Cuarta pregunta: ¿Para qué crees que sirve el estómago?

Con la cuarta pregunta pretendíamos saber para qué creen que sirve el estómago. En nuestras predicciones no esperábamos que nos dieran una respuesta específica, sino que creíamos que a través de preguntas de reformulación consiguieran darnos algún tipo de información sobre lo que consideraban. Sin embargo, nos sorprendió que, al tratarse de una entrevista individualizada, algunos de los alumnos coincidieran a la hora de dar sus respuestas, ya que, nosotras no teníamos expectativas al respecto. De hecho, a la hora de responder, tres de ellos expresaron que servía para tragar, uno que servía para guardar la comida, otro de ellos que servía para avisarle de cuando tenía hambre y finalmente, otro no supo responder.

Figura 4. Resultados a la cuestión ¿Para qué crees que sirve el estómago?

\section{¿ PARA QUÉ CREES QUE SIRVE EL ESTÓMAGO?}

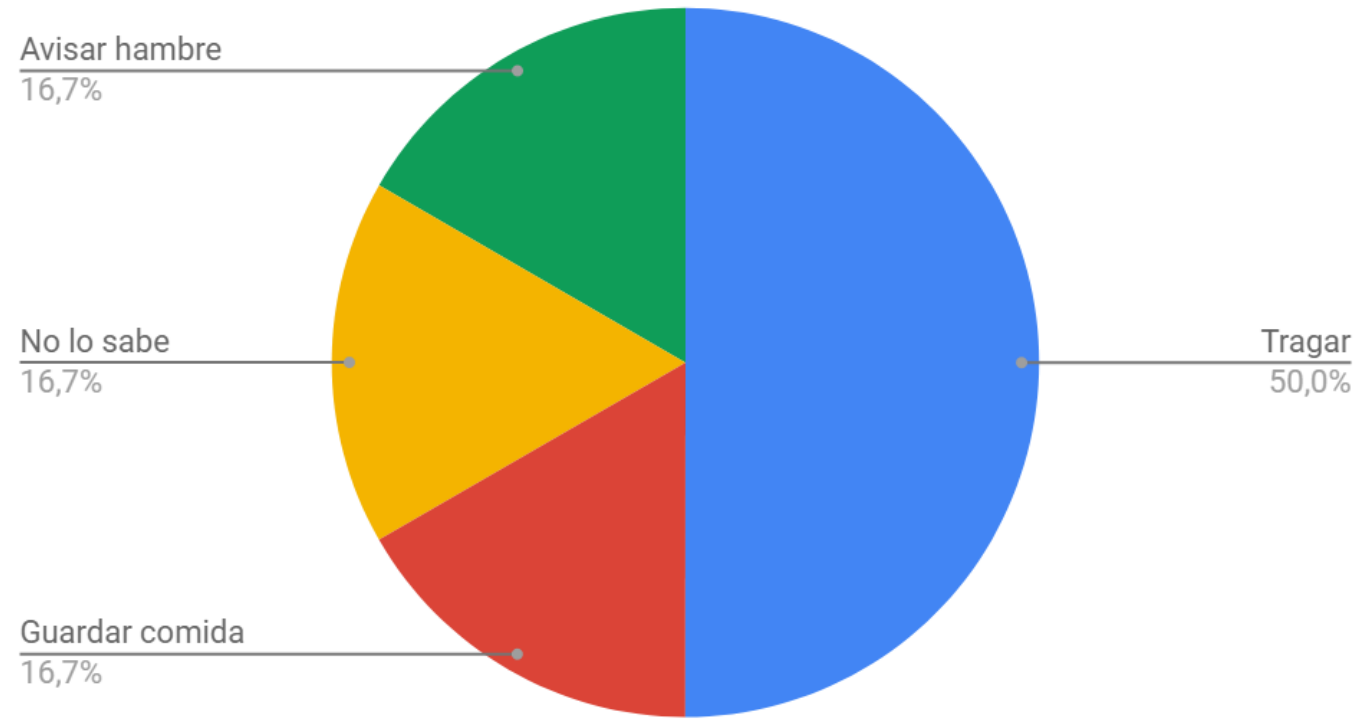

- Quinta pregunta: Cuando te comes un plátano, ¿por dónde crees que pasa?

En la quinta pregunta, queríamos comprobar si saben por donde pasa el alimento una vez que es ingerido. En este caso, elegimos como ejemplo un plátano. Para ello, le facilitamos una silueta del cuerpo humano con la cabeza girada, y con pintura tenían que trazar el recorrido que pensaban que hacía el alimento dentro del cuerpo después de ser consumido. Con ello pudimos ver que, dos niños piensan que va de la boca a la barriga, mientras que otros dos de los alumnos creen que va de la boca al pie. Otro de ellos considera que se desplaza de la boca a la pierna, para darle a la misma fuerza. Finalmente uno consiguió terminar el recorrido llegando hasta el ano. 
Figura 5. Resultados al recorrido del plátano

\section{CUANDO TE COMES UN PLÁTANO, ¿POR DÓNDE CREES QUE PASA?}

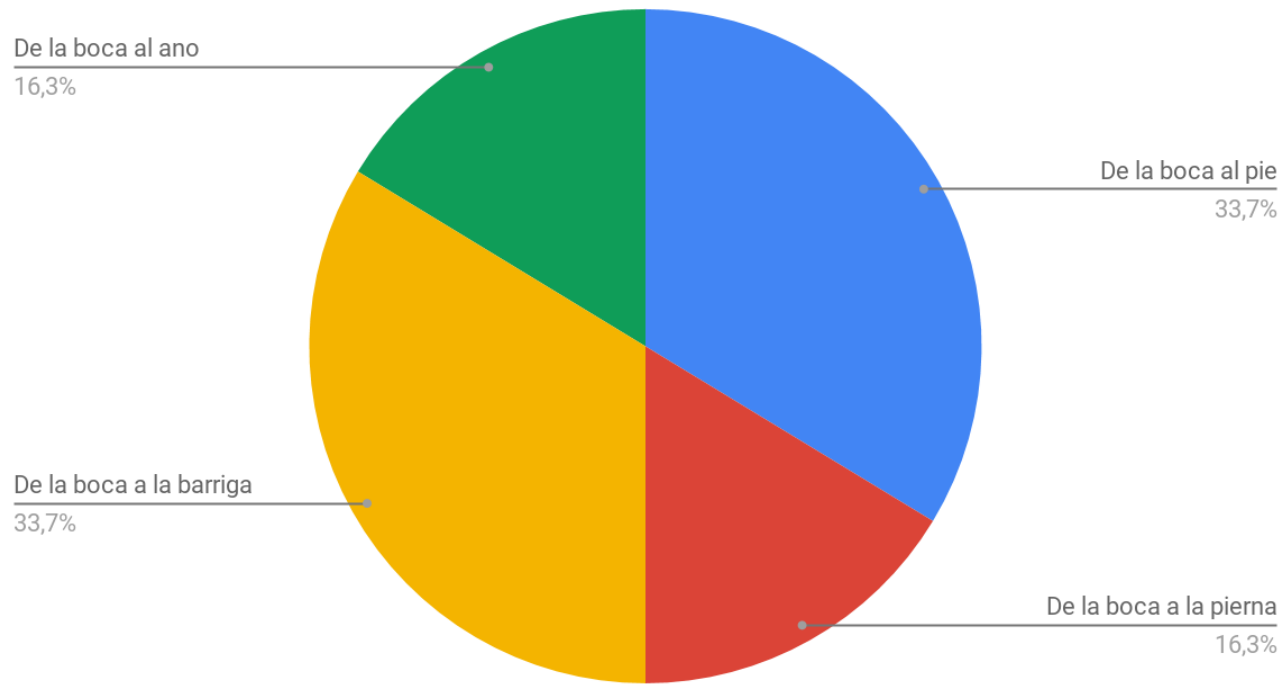

- Sexta pregunta: ¿Crees que la comida sale por algún sitio?

En esta última pregunta, lo que pretendíamos era que los niños nos dijeran si la comida sale por algún lado una vez que está en el estómago, relacionado con ello, la observación de si alguno de ellos anteriormente había tenido en cuenta en su recorrido, de forma indirecta a los intestinos grueso y delgado. Cuatro de los alumnos entrevistados respondieron de forma negativa a esta pregunta, afirmando que el alimento ingerido no sale por ningún lado. Así pues, tan solo dos de los alumnos nos dieron la respuesta que esperábamos, diciendo que el plátano sí salía del cuerpo, aunque tan solo uno de ellos supo responder a la pregunta ¿a dónde va?, asegurando que el alimento iba al váter. 
Figura 6. Resultados a la cuestión ¿Crees que la comida sale por algún sitio?

\section{¿CREES QUE LA COMIDA SALE POR ALGÚN SITIO?}

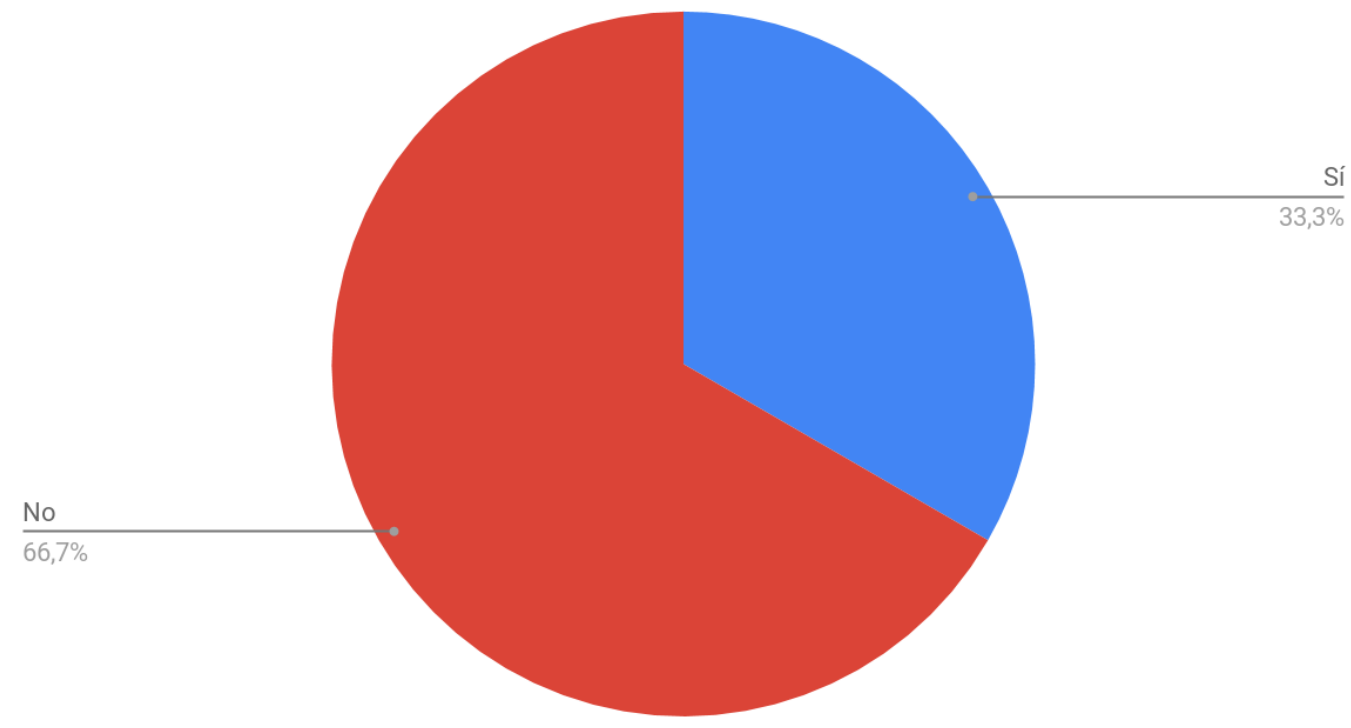

\section{CONCLUSIONES}

Una vez realizada la entrevista y para concluir este trabajo, comenzaremos por llevar a cabo una comparación entre lo que previamente eran nuestras predicciones y lo que finalmente resultaron ser las respuestas de los alumnos entrevistados.

En lo referido a la primera cuestión que planteamos, pensábamos que dirían que en el estómago tenemos comida, gases o desechos, pero no todas sus respuestas coincidían con esta idea previa, ya que solo dos de ellos hicieron referencia a la comida, mientras que el resto opinó cosas que no habíamos previsto, tales como sangre, huesos e incluso el cerebro.

A la hora de predecir las respuestas de la segunda cuestión, creíamos que los niños de cuatro años sabrían ubicar el estómago de forma aproximada con el gomet que les proporcionamos y aunque la mayoría de sus respuestas se correspondía con la predicción, dos de los niños lo situaron en la zona de la garganta.

Unida a esa cuestión, realizamos otra en lo que respecta al tamaño del estómago, en la cual encontramos una variedad de opiniones. Desde nuestro punto de vista, las respuestas fueron dados de manera aleatoria, ya que no encontramos fundamento en el motivo por el cual consideran que el estómago es grande, mediano o pequeño. Uno de los entrevistados se apoyó en su propio cuerpo para afirmar que el tamaño del estómago era alargado, pero consideramos que el resto de alumnos no llegaron a relacionar los términos vinculados al tamaño con el estómago, por lo que se limitaron a decir lo que se les ocurrió en ese momento. 
En lo que respecta a la cuarta pregunta planteada, antes de llevar a cabo la entrevista, creíamos que los niños no serían capaces de darnos una respuesta concisa sin la ayuda de preguntas de reformulación. Tres de los alumnos afirmaron que el estómago sirve para tragar, lo cual nos llamó la atención, dado que no se trata de una respuesta esperada y además, lo dijeron con total rotundidad. Por otra parte, otro de los alumnos indicó que el estómago servía para la comida, lo cual podemos relacionar con su respuesta a la primera cuestión planteada durante la entrevista, en la que dijo que en la barriga podemos encontrar comida y bebida. Es por ello, que consideramos correcto afirmar que el entrevistado supo establecer una correspondencia entre los términos "barriga" y "estómago".

Por otro lado, en relación al recorrido que hace un plátano una vez se ingiere, planteado en la quinta cuestión, creímos que sabrían establecer correctamente el mismo, pero no fue así, ya que, tan solo un niño fue capaz de marcar de forma completa el recorrido teniendo en cuenta que el alimento sale del cuerpo. Hubo dos que señalaron el recorrido hasta el estómago, sin comentar ni marcar que el plátano sería expulsado después del cuerpo. Además, hubo algunos entrevistados que pensaron que la comida se quedaba en la pierna y en el pie, por lo que marcaron su recorrido hasta aquellas zonas. Respecto a los alumnos que señalaron que el plátano se quedaba en el pie, no encontramos justificación a su respuesta ya que tampoco la cuestionamos, pues simplemente se dio por válida como idea previa. Sin embargo, el niño que indicó que el plátano llegaba hasta la pierna realizó una justificación propia de ello, comentando que allí le daría fuerza para esta. Probablemente, esta respuesta se deba a que el niño tenga interiorizada la idea de que comer fruta es sano porque nos aporta energía, de manera que él mismo estableció una relación basada en esa idea.

Finalmente, en lo relacionado con la expulsión de alimentos, establecimos que responderían de manera afirmativa a la pregunta de si la comida sale del cuerpo, y que sabrían decir a dónde va a parar el alimento. Sin embargo, únicamente el niño que estableció el recorrido completo del plátano, aseguró además, que este era expulsado por el ano y que iba a parar al váter. Además, aunque otro de los entrevistados dijo que el alimento era expulsado del cuerpo, no logró indicar por donde lo hacía. Los cuatro niños restantes aseguraban que la comida ingerida no salía por ningún lado, hecho que nos sorprendió en un principio, ya que para esta pregunta sí teníamos unas expectativas enfocadas a una respuesta positiva.

Una vez que hemos realizado la entrevista y cotejado los resultados, nos damos cuenta, al comparar las respuestas de los niños con nuestras predicciones, de que en muchos de los aspectos, nos encontrábamos equivocadas. Pensábamos que a la edad de cuatro años los alumnos sabrían responder sin problema a la mayoría de las preguntas planteadas en un principio. Sin embargo, algunos de ellos no supieron contestar de la forma esperada a ciertas cuestiones, y en algunas de sus respuestas, nos 
sorprendieron significativamente. Un claro ejemplo de ello se muestra en la respuesta dada por una alumna a la primera pregunta de la entrevista realizada, en la que afirma que en la barriga se encuentra el cerebro. Además, en las preguntas cuyas respuestas creíamos más evidentes, como en el caso de la última cuestión formulada, en la que se preguntaba si la comida salía por algún lado, no todos supieron responder acorde a lo esperado.

Una de las principales conclusiones que hemos sacado en claro con la realización de este trabajo es que los alumnos de cuatro años, edad a la que iba destinada la entrevista, no poseen un amplio conocimiento sobre su cuerpo, más concretamente sobre el sistema digestivo, tal y como nos muestran las respuestas de cada uno de los entrevistados. Sin embargo, consideramos que en una edad más avanzada, sí podrían habernos proporcionado una información con mayor seguridad y conocimientos.

Cada niño es un mundo, y aunque puedan compartir determinadas características debido a su edad, no todos tienen la misma capacidad de raciocinio ante ciertas preguntas o poseen los mismos conocimientos que otros.

En definitiva, creemos que en la etapa de educación infantil los niños no tienen unos conocimientos demasiado amplios sobre el cuerpo humano, y más concretamente, en la etapa de cuatro años, generalmente no conocen mucho acerca de su propio cuerpo, a pesar de que existan niños, que como hemos mencionado anteriormente, puedan tender hacia una mayor capacidad de raciocinio que otros. Es por ello que las preguntas que se le puedan realizar al respecto, serán contestadas sin estar demasiado justificadas, o incluso contestadas al azar. Y es que, el contenido que hemos escogido para realizar el trabajo que nos ocupa, a pesar de ser trabajado en infantil, puede resultar algo difícil para los alumnos, en función de la profundización que se le haya dado en el aula o el tiempo que se haya podido dedicar al mismo. No obstante, gracias a la información proporcionada por la maestra tutora del centro, podemos afirmar que a la edad de cinco años se les empieza a dar mayor importancia a nombres de órganos y huesos, por lo que las respuestas que nos proporcionarían los alumnos a estas edades, podrían ser más idóneas a nuestras predicciones.

\section{7 “HOJA DE ACEPTACIÓN"}

El trabajo realizado, se ha llevado a cabo de una manera consensuada, es decir, todas estábamos de acuerdo en el tema elegido, en las preguntas elaboradas para los niños, en los materiales que se iban a utilizar para apoyar las preguntas, los contenidos trabajados en el trabajo, al colegio al que íbamos a ir, como representar los datos recogidos, además de trabajar de una manera cooperativa y estando todas a favor de realizar cada cosa. 


\section{BIBLIOGRAFÍA}

Catlin, S. (2013). Learning about places around the world. En Scoffham, S. (Ed.), Teaching Geography Creatively. (pp. 59-71). Londres, Reino Unido: Routledge.

Cooper, H. (2002). History in the early years. (Trad. cast.: Didáctica de la historia en la educación infantil y primaria. Madrid, España: Morata, 2002).

Feliu, M., Jiménez, L., Arbonés, G., Bardavio, A., \& Calabuig, S. (2015). Ciencias sociales y educación infantil (3-6). Barcelona, España: Graó.

Piaget, J. (1952). The Child's Conception of Number, Londres, Routledge. (Trad. cast.: Génesis del número en el niño. Buenos aires, Guadalupe, 1975).

Piaget, J. (1956). The Child's Conception of Time, Londres, Routledge. (Trad. cast.: El Desarrollo de la noción de tiempo en el niño. México, Fondo de Cultura Económica, 1978).

Restrepo, B. (2005). Aprendizaje basado en problemas (ABP): una innovación didáctica para la enseñanza universitaria. Educación y educadores. Volumen 8. p. 2-3. Recuperado de http://educacionyeducadores.unisabana.edu.co/index.php/eye/article/view/562/654

Trigueros, F.J., Arias, L., Miralles, P., Molina, S., \& Rodríguez, R.A. (2013.) Didáctica De Las Ciencias Sociales En Los Cursos De Grado De Educación Infantil. Murcia, España: Diego Marín. 
ANEXOS

Anexo I

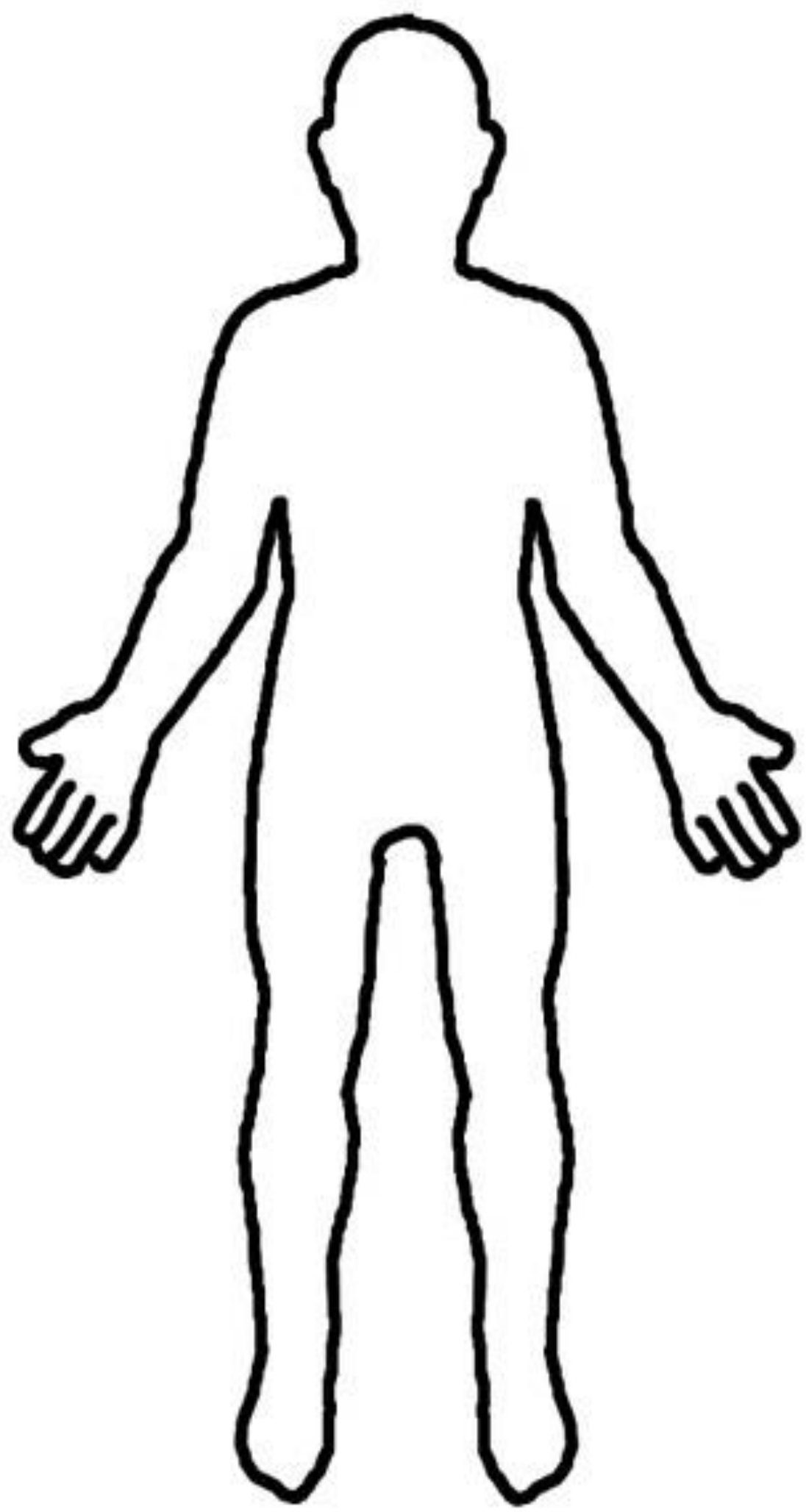


South Florida Journal of Development, Miami, v.2, n.1, p. 941-961, ian./feb. 2021. ISSN 2675-5459

SOUTH FLORIDA

JOURNAL OF DEVELOPMENT

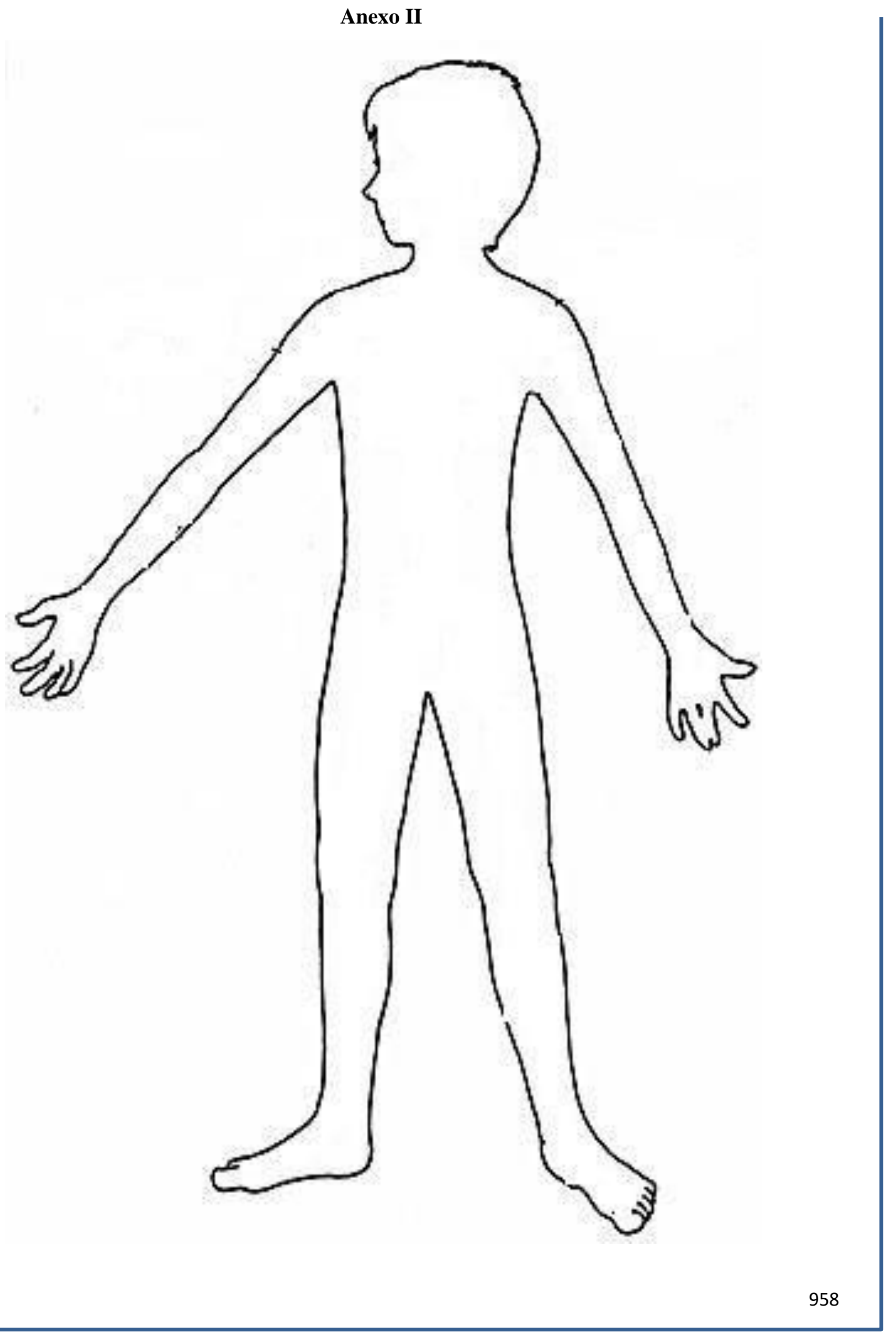




\section{Anexo II}

A mi hijo de de E. Infantil, a formar parte de un estudio muestral, organizado por un alumno de la Universidad de Murcia, sobre los conocimientos, en alumnos de Educación Infantil، sobre el aparato digestivo. Asi como el tratamiento de los datos que de ello deriven.

Dicho estudio será anónimo. Se realizará en el mismo colegio. Y no durará más de diez minutos 


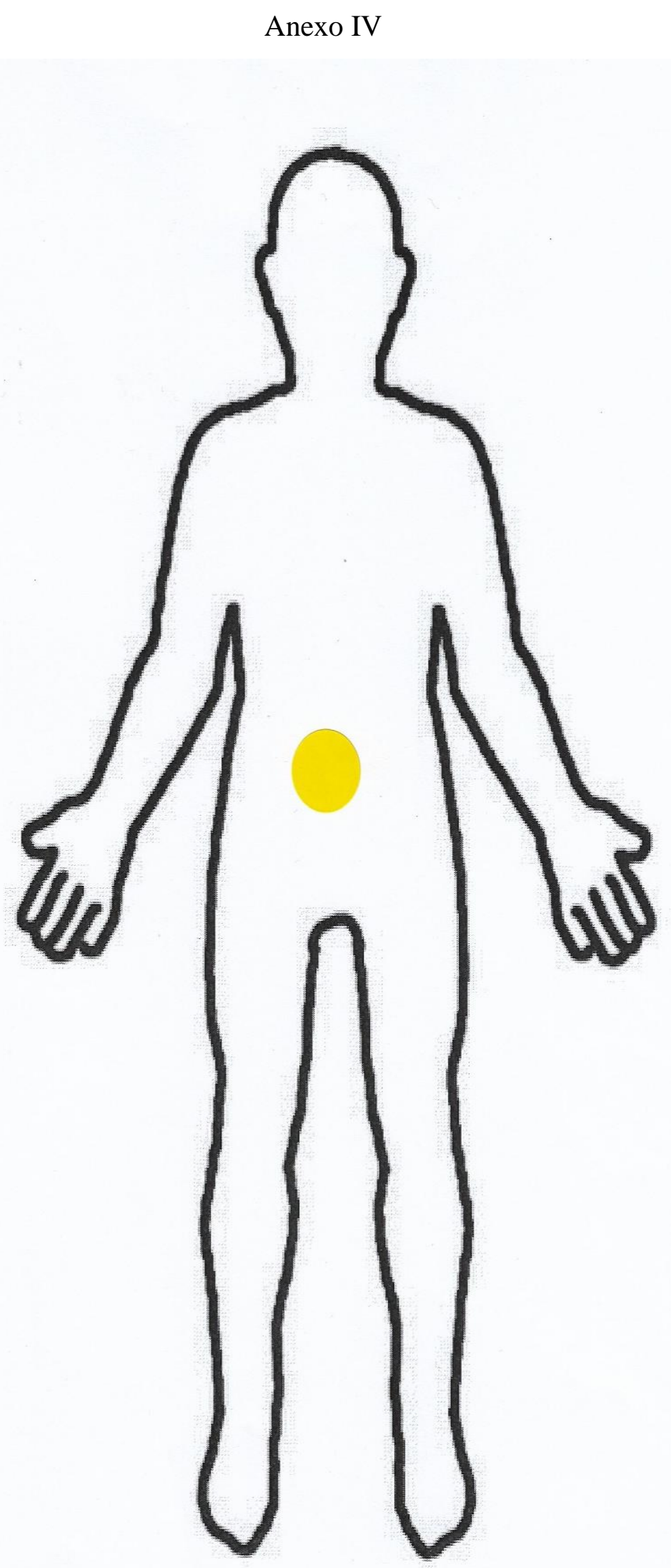




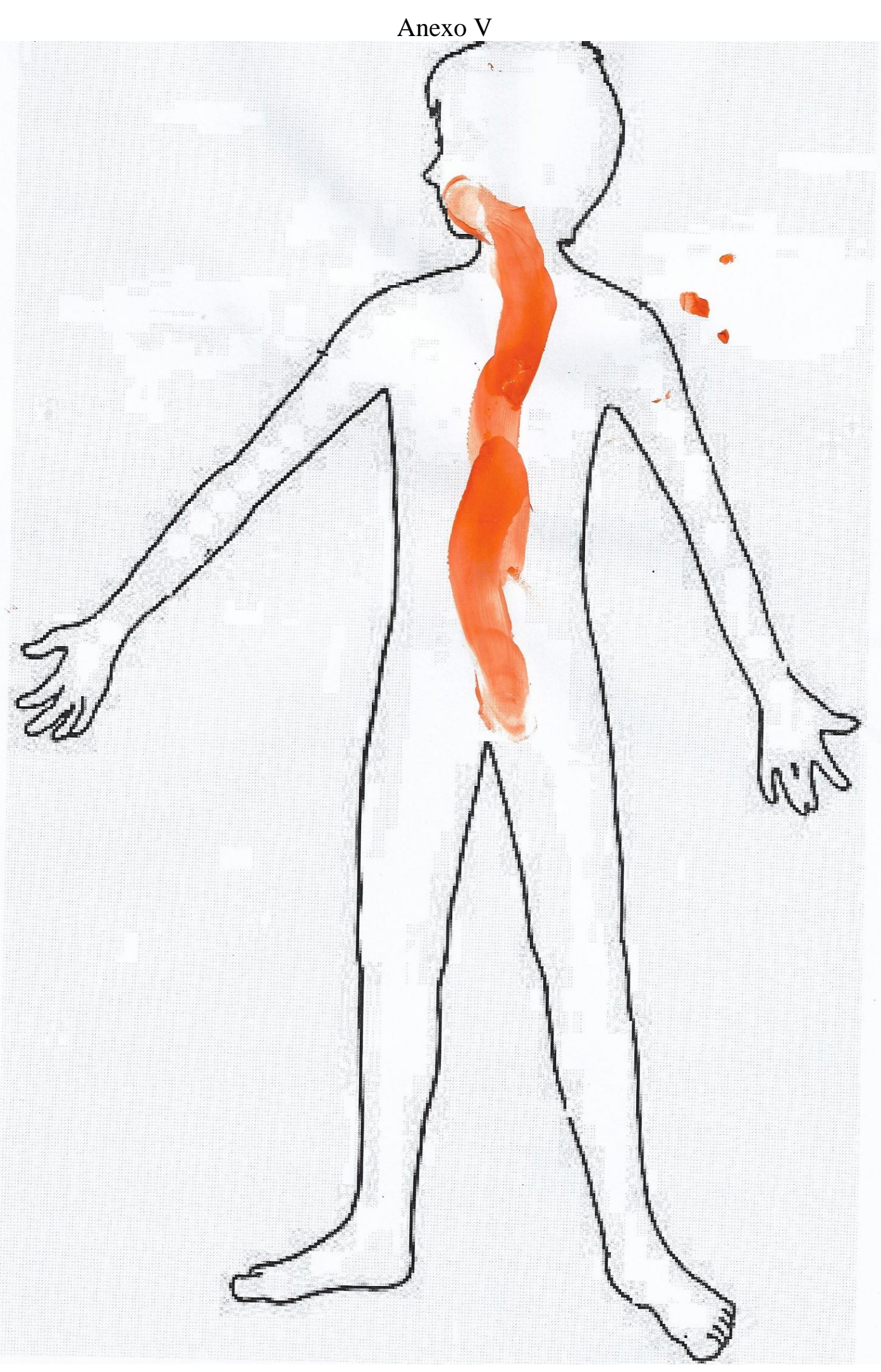

